\title{
Pleural plaques and exposure to mineral fibres in a male urban necropsy population
}

\author{
A Karjalainen, P J Karhunen, K Lalu, A Penttilä, E Vanhala, P Kyyrönen, A Tossavainen
}

\begin{abstract}
Objectives-The study aimed to evaluate the risk of pleural plaques according to the degree of past exposure to asbestos, type of amphibole asbestos, and smoking, as well as to estimate the aetiologic fraction of asbestos as a cause of plaques among urban men.
\end{abstract}

Methods-The occurrence and extent of pleural plaques were recorded at necropsies of 288 urban men aged 33 to 69 years. The pulmonary concentration of asbestos and other mineral fibres was analysed with scanning electron microscopy. The probability of past exposure was estimated from the last occupation.

Results-Pleural plaques were detected in $58 \%$ of the cases and their frequency increased with age, probability of past occupational exposure to asbestos, pulmonary concentration of asbestos fibres, and smoking. The risk of both moderate and widespread plaques was raised among asbestos exposed cases, and the risk estimates were higher for widespread plaques than for moderate plaques. The age adjusted risk was higher for high concentrations of crocidolite/amosite fibres than for anthophyllite fibres. The aetiologic fraction of pulmonary concentration of asbestos fibres exceeding $0 \cdot 1$ million fibres/g was $43 \%$ for widespread plaques and $24 \%$ for all plaques. The median pulmonary concentrations of asbestos fibres were about threefold greater among cases with widespread plaques than among those without plaques. No increased risk of pleural plaques was associated with raised total concentrations of non-asbestos fibres.

Conclusion-The occurrence of pleural plaques correlated closely with past exposure to asbestos. The risk was dependent on the intensity of exposure. Due to methodological difficulties in detecting past exposures to chrysotile and such low exposures that may still pose a risk of plaques, the aetiologic fractions calculated in the study probably underestimate the role of asbestos.

(Occup Environ Med 1994;51:456-460)

A relation between exposure to asbestos and the occurrence of pleural plaques has been shown in numerous studies. Only a few studies, however, have evaluated the risk of pleural plaques according to the degree of exposure, or estimated the aetiologic fraction of asbestos exposure as a cause of pleural plaques. ${ }^{1}$ The aim of our study was to analyse these issues in a series of 300 male urban necropsy cases. Exposure to anthophyllite asbestos has been common in Finland, and endemic pleural plaques have been reported after environmental exposure to anthophyllite. ${ }^{2-4}$ Therefore an effort was also made to evaluate the role of anthophyllite as a cause of pleural plaques in the Finnish population.

\section{Material and methods STUDY POPULATION}

The study comprised all sudden, unexpected deaths of men aged 35 to 69 years who had died in Helsinki, and who had been examined at necropsy between 15 January 1991 and 30 January 1992 at the Department of Forensic Medicine, University of Helsinki. The cases where the body was combusted or macerated were excluded. Inadvertedly two cases aged 33 years were included. The necropsy series ( $n=300$ ) comprises $30 \%$ of all male deaths in this age group in the area. One relative of each deceased person was interviewed personally with a standardised questionnaire including questions on smoking habits. The interview was conducted in 167 cases.

Table 1 gives the distribution of causes of death among the study population. About $60 \%$ of the deaths were due to a disease, and $80 \%$ of these were cardiovascular diseases. There were no deaths due to mesothelioma or asbestosis. Three cases of lung cancer occurred. These were not suspected to be asbestos related; nor was asbestosis evidenced at their necropsy.

\section{DETERMINATION OF PLEURAL PLAQUES}

The site and size of pleural plaques was determined in 288 cases of the series. All shining white thickenings of the parietal pleura with well defined borders were defined as plaques. The detection of plaques was based on their macroscopical appearance only; no histological verification was used. The dimensions of plaques in the right and left hemithorax and the diaphragm were recorded. The maximum total area of plaques was about $600 \mathrm{~cm}^{2}$. The cases were classified into three groups according to the total surface area of the plaques: (1) no plaques: cases where no plaques could be detected at necropsy; (2) moderate plaques: cases with bilateral plaques with a total area less than $100 \mathrm{~cm}^{2}$ and all cases with 
Table 1 Causes of death among 300 Finnish male necropsy cases

\begin{tabular}{lrll}
\hline & \multicolumn{4}{c}{ Age (y) } \\
\cline { 2 - 4 } Cause of death & No & Range & Mean \\
\hline Disease & 179 & $36-69$ & $54 \cdot 8$ \\
Suicide & 52 & $33-69$ & $48 \cdot 7$ \\
Accidental & 41 & $35-65$ & $48 \cdot 3$ \\
Alcohol intoxication & 21 & $36-62$ & $47 \cdot 7$ \\
Not defined & 7 & $37-69$ & $46 \cdot 6$ \\
All & 300 & $33-69$ & $52 \cdot 2$ \\
\hline * Includes 18 cases of accidental intoxication, 14 cases of acci- \\
dental falling, three homocides, two cases of accidental suffo- \\
cation, two traffic accident, one case of accidental explosion, \\
and one case of hypothermia. †Could not be determined \\
whether the death was due to an accident or a suicide.
\end{tabular}

unilateral plaques only; (3) widespread plaques: cases with bilateral plaques with a total area of at least $100 \mathrm{~cm}^{2}$.

The necropsies and the determination of the plaques were carried out by three pathologists (94 to 98 necropsies each). No significant differences in the determination of plaques between the pathologists were found when this was applied as a variable in the statistical model (adjusted for age and asbestos exposure of the necropsy cases).

\section{OCCUPATIONAL HISTORY}

The last occupation of the cases was derived from the necropsy records, and was used to classify the cases into four exposure categories according to the probability of exposure to asbestos as follows (codes of the Nordic Classification of Occupations ${ }^{5}$ in parentheses):

\section{Probable exposure}

Construction occupations (codes 621-629, $755,761)$.

\section{Possible exposure}

All other industrial occupations (codes 000-007, 501-619, 631-754, 756-759, 762-902, 940-949).

\section{Unlikely exposure}

Office type occupations, health care occupations, and agricultural work (codes 008-499, 903-939, 951-999).

\section{Unknown exposure}

Cases without any information on occupation; most of them with only a notification "retired" in the necropsy record.

\section{ELECTRON MICROSCOPY}

A lung tissue sample from the peripheral left upper lobe was stored in $4 \%$ formaldehyde and used for electron microscopic fibre analysis. A low temperature ashing technique was used to remove organic tissue. Fibres were detected with a JEOL 100 CX-ASID4D electron microscope in scanning mode with a magnification of $\times 5000 .^{6}$ All inorganic particles having a length to width ratio greater than 3 and roughly parallel sides were defined as fibres and counted. Fibres longer than $1 \mu \mathrm{m}$ could be detected. A minimum of 200 viewing fields was evaluated to find at least 4 to 30 fibres per sample, depending on the density.
With this procedure an analytical sensitivity (one fibre per sample) of about 0.07 million fibres per $g(f / g)$ dry tissue was reached. If only 1 to 3 fibres per sample were detected, a numerical concentration was still calculated and used in the analyses.

An energy dispersive $x$ ray microanalyser (Tracor TN 5500) was used to determine the fibre type. The intensity ratios of $\mathrm{Si}, \mathrm{Mg}, \mathrm{Fe}$, $\mathrm{Ca}$, and $\mathrm{Na}$ were used in identification by comparing peak ratios to standard spectra. Amosite and crocidolite have almost similar $x$ ray spectra and are distinguished poorly. They are therefore not presented separately. Chrysotile fibres are poorly detected with scanning electron microscopy and consequently a low concentration of chrysotile fibres was detected in one sample only. Low concentrations of tremolite fibres were detected in six samples. Chrysotile and tremolite fibres are included in the number of total asbestos fibres, but are not reported separately.

\section{STATISTICAL ANALYSES}

The statistical analyses were performed with the multinomial logistic regression model. The confidence intervals ( $95 \%$ CIs) of the variables are based on their standard errors. The common odds ratios (ORs) for risk variables were also calculated with a cumulative odds model of the ordinal logistic regression. The conclusions drawn from the results of these two models were similar. For the sake of clarity, only the results of the multinomial logistic regression are presented. The aetiologic fractions were calculated with the fitted frequencies from the multinomial logistic regression.

\section{Results}

Pleural plaques were detected in $58 \%$ of the cases. The frequency of plaques increased with age, probability of occupational exposure to asbestos, and the concentration of asbestos fibres in lung tissue, but not with the total concentration of inorganic fibres other than asbestos (figure and table 2). More than $80 \%$

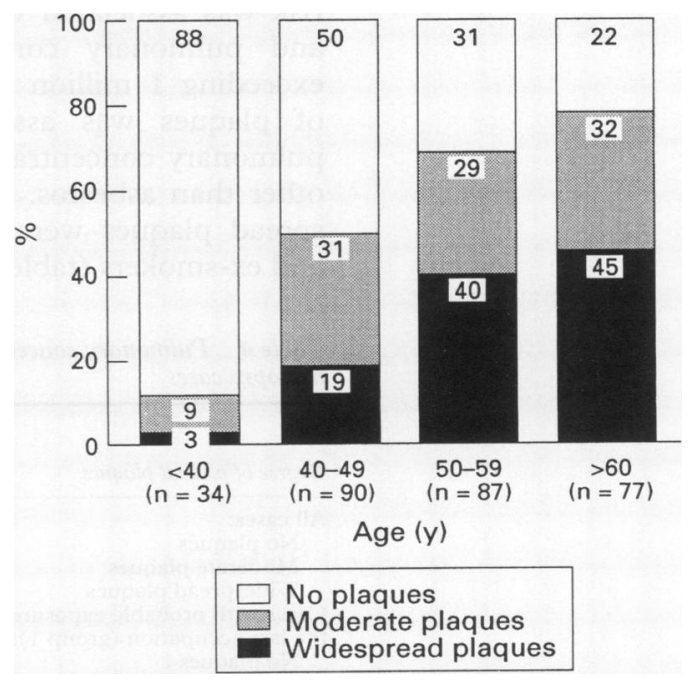

Occurrence of pleural plaques by age in 288 Finnish male urban necropsy cases. 
Table 2 Age adjusted ORs of pleural plaques according to exposure to mineral fibres and smoking among 288 Finnish male necropsy cases

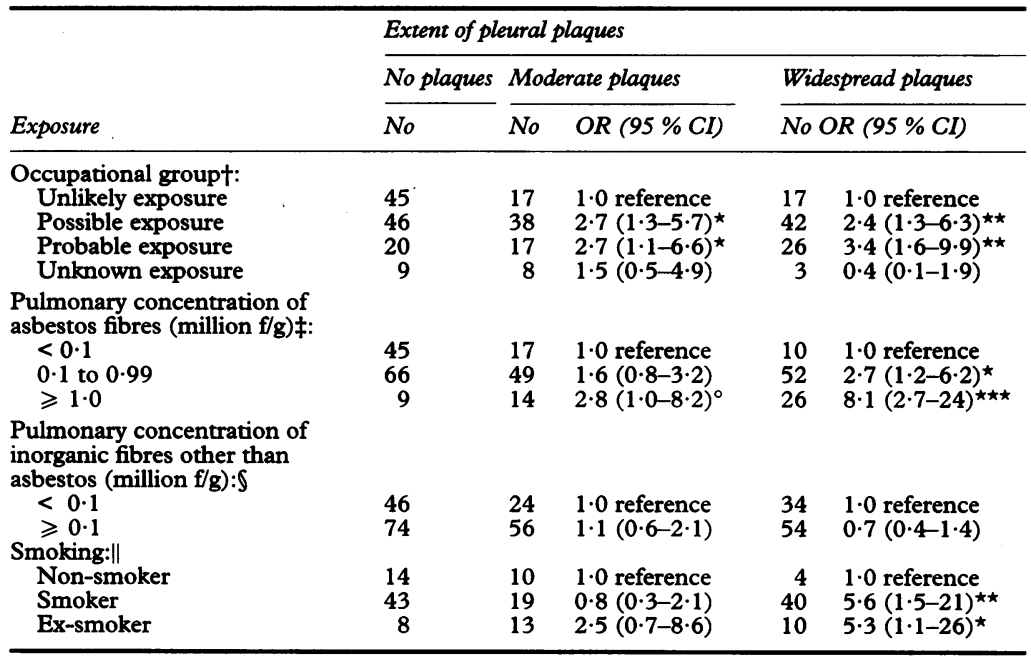

${ }^{\circ} \mathrm{p}<0.1 ;{ }^{\star} \mathrm{p}<0.05 ;{ }^{\star \star} \mathrm{p}<0.01 ;{ }^{\star \star \star} \mathrm{p}<0.001$. HAdjusted for age. $\ddagger$ Adjusted for age and pulmonary concentration of inorganic fibres other than asbestos. SAdjusted for age and pulmonary concentration of asbestos fibres. \|Adjusted for age and pulmonary concentration of asbestos fibres. Smoking habits known for 161 cases.

Table 3 Age adjusted and unadjusted ORs of pleural plaques according to pulmonary concentration of anthophyllite and crocidolitelamosite fibres among 288 Finnish male necropsy cases

\begin{tabular}{|c|c|c|c|c|c|c|c|}
\hline \multirow[b]{2}{*}{$\begin{array}{l}\text { Pulmonary fibre } \\
\text { concentration } \\
\text { (million flg) }\end{array}$} & \multirow{2}{*}{$\begin{array}{l}\text { No plaques } \\
\text { No }\end{array}$} & \multicolumn{3}{|c|}{ Moderate plaques } & \multicolumn{3}{|c|}{ Widespread plaques } \\
\hline & & No & $\begin{array}{l}\text { OR } \\
\text { unadjusted } \\
\text { for age }\end{array}$ & $\begin{array}{l}\text { OR } \\
\text { adjusted } \\
\text { for age }\end{array}$ & No & $\begin{array}{l}\text { OR } \\
\text { unadjusted } \\
\text { for age }\end{array}$ & $\begin{array}{l}\text { OR } \\
\text { adjusted } \\
\text { for age }\end{array}$ \\
\hline \multicolumn{8}{|l|}{ Anthophyllite: $\dagger$} \\
\hline$<0.1$ & 60 & 19 & $1 \cdot 0$ & $1 \cdot 0$ & 17 & 1.0 & $1 \cdot 0$ \\
\hline 0.1 to 0.49 & 45 & 40 & $2 \cdot 7^{\star \star}$ & 1.7 & 42 & $3 \cdot 0^{\star \star}$ & 1.5 \\
\hline$\geqslant 0.5$ & 15 & 21 & $3 \cdot 8^{\star \star}$ & $2 \cdot 2^{0}$ & 29 & $4 \cdot 5^{\star \star \star}$ & $1 \cdot 8$ \\
\hline \multicolumn{8}{|c|}{ Crocidolite/amosite $\ddagger$} \\
\hline$<0.1$ & 88 & 49 & $1 \cdot 0$ & $1 \cdot 0$ & 38 & $1 \cdot 0$ & $1 \cdot 0$ \\
\hline 0.1 to 0.49 & 27 & 21 & $1 \cdot 1$ & 1.5 & 28 & $1.9^{\circ}$ & $2 \cdot 8^{\star \star}$ \\
\hline$\geqslant 0.5$ & 5 & 10 & $2 \cdot 7^{\circ}$ & $2 \cdot 9$ & 22 & $7 \cdot 4^{\star \star \star}$ & $7 \cdot 7^{\star \star \star}$ \\
\hline
\end{tabular}

${ }^{\circ} \mathrm{p}<0.1 ;{ }^{\star} \mathrm{p}<0.05 ;{ }^{\star \star} \mathrm{p}<0.01 ;{ }^{\star \star \star} \mathrm{p}<0.001$. †Adjusted for pulmonary concentration of crocidolite/amosite fibres. $¥$ Adjusted for pulmonary concentration of anthophyllite fibres.

of cases with $\geqslant 1$ million asbestos $\mathrm{f} / \mathrm{g}$ in lung tissue had plaques. Plaques were also detected, however, in $43 \%$ of the cases with unlikely exposure to asbestos according to their occupation, and in $38 \%$ of those with $<0.1$ million asbestos $\mathrm{f} / \mathrm{g}$ in lung tissue.

The risk estimates of both moderate and widespread plaques were raised among asbestos exposed cases (table 2). The highest risk was associated with widespread plaques and pulmonary concentration of asbestos exceeding 1 million $\mathrm{f} / \mathrm{g}(\mathrm{OR}=8 \cdot 1)$. No risk of plaques was associated with increased pulmonary concentrations of inorganic fibres other than asbestos. Increased risks of widespread plaques were found among smokers and ex-smokers (table 2). The overall effect of smoking (smokers and ex-smokers combined) on pleural plaques was highly significant $\left(\chi^{2}=19 \cdot 1, \mathrm{p}<0 \cdot 001\right)$.

Significantly raised ORs were found for pulmonary concentrations of crocidolite/ amosite fibres and plaques, whereas the ORs of anthophyllite were not significantly increased when adjusted for age (table 3 ). Interestingly, when no adjustment for age was used, a significantly increased risk of plaques was associated with increased concentrations of anthophyllite. Adjustment for age thus increased the risk estimates of crocidolite/ amosite concentrations and decreased the risk estimates of anthophyllite fibres.

The risk estimates shown in table 2 give an aetiologic fraction of $24 \%$ of all pleural plaques and $43 \%$ of the widespread plaques for pulmonary concentrations of asbestos fibres of $\geqslant 0.1$ million $\mathrm{f} / \mathrm{g}$. When the last occupation (probable or possible exposure to asbestos) was used as an indicator of exposure, the corresponding figures were $26 \%$ and $29 \%$ respectively. Similar calculations resulted in an aetiological fraction of $12 \%$ for both anthophyllite and crocidolite/amosite fibres.

The median of the asbestos fibre concentrations and the proportion of cases with $\geqslant 1$ million $\mathrm{f} / \mathrm{g}$ were two to four times higher among cases with widespread plaques than among those without plaques (table 4). Similar results were found both when all cases were analysed and when only cases with probable exposure history were used in the analyses. The concentrations were not adjusted for age. The cases with widespread plaques were on the average about 8 years older than the cases with no plaques.

\section{Discussion}

The association between pleural plaques and previous occupational exposure to asbestos was confirmed in this study. The risk estimates were higher for pulmonary concentrations of $\geqslant 1$ million $\mathrm{f} / \mathrm{g}$ than for concentrations of 0.1 to 1 million $\mathrm{f} / \mathrm{g}$, indicating a dose response relation. In both of these categories the risk of widespread plaques was higher than the risk of moderate plaques. As we could adjust for age only, and not directly for the effect of latency, it is difficult to intrepret the dependence of the size of plaques on the degree of exposure. A similar relation was found in a previous Italian study. ${ }^{\text {? }}$

Despite the strong association between

Table 4 Pulmonary concentration of asbestos fibres according to the degree of pleural plaques among 288 Finnish male necropsy cases

\begin{tabular}{|c|c|c|c|c|c|c|}
\hline \multirow[b]{2}{*}{ Degree of pleural plaques } & \multicolumn{5}{|c|}{ Concentration of asbestos fibres in lung tissue (million $\mathrm{f} / \mathrm{g}$ ) } & \multirow{2}{*}{$\begin{array}{l}\text { Mean age } \\
\text { (y) }\end{array}$} \\
\hline & No & Range & Median & Mean & $\geqslant 1 \cdot 0(\%)$ & \\
\hline \multicolumn{7}{|l|}{ All cases: } \\
\hline No plaques & 120 & $0-2 \cdot 9$ & $0 \cdot 16$ & 0.32 & 8 & $48 \cdot 0$ \\
\hline Moderate plaques & 80 & $0-4 \cdot 7$ & 0.40 & 0.59 & 21 & 53.5 \\
\hline Widespread plaques & 88 & $0-160$ & 0.57 & $3 \cdot 7$ & 30 & $56 \cdot 6$ \\
\hline \multicolumn{7}{|c|}{$\begin{array}{l}\text { Cases with probable exposure to asbestos according to } \\
\text { the last occupation (group 1): }\end{array}$} \\
\hline No plaques & 20 & $0-1 \cdot 8$ & 0.37 & 0.57 & 20 & $48 \cdot 1$ \\
\hline Moderate plaques & 17 & $0-2 \cdot 5$ & 0.66 & $0 \cdot 83$ & 29 & $50 \cdot 5$ \\
\hline Widespread plaques & 26 & $0-160$ & 0.92 & $8 \cdot 4$ & 46 & $56 \cdot 4$ \\
\hline
\end{tabular}


exposure to asbestos and the occurence of plaques, a significant number of all plaques ( $14 \%$ of the widespread and $24 \%$ of the moderate plaques) were detected in cases with less than 0.1 million $\mathrm{f} / \mathrm{g}$. As a significantly raised risk of plaques was associated with pulmonary asbestos concentrations from 0.1 to $1.0 \mathrm{mil}-$ lion $\mathrm{f} / \mathrm{g}$, some risk is also likely to be associated with concentrations below $0 \cdot 1$ million $\mathrm{f} / \mathrm{g}$, which were not quantifiable with our method. The aetiologic fractions calculated in this study are thus underestimations of the fraction of plaques attributable to asbestos in the study population. Actually the criteria used for asbestos exposure (last occupation or asbestos fibre concentration above 0.1 million f/g) refer mainly to occupational exposure to asbestos, neglecting the role of environmental and domestic exposures. Also the use of the last occupation as an exposure indicator probably resulted in misclassification, as there is a long latency time between the onset of exposure and the occurrence of plaques.

Chrysotile is cleared more rapidly from the lungs than the amphiboles, and even if transmission electron microscopy is used, the chrysotile content of lung tissue is not an equally representative measure of past cumulative chrysotile exposures as is the amphibole content for amphibole exposures. ${ }^{8}$ As about $40 \%$ of all asbestos used in Finland during 1918-88 consisted of amphiboles ${ }^{9}$ and a mixed exposure to chrysotile and amphiboles took place in most of the industrial applications, the amphibole content in the lung tissue is a reasonably representative indicator of past exposure to asbestos. Yet some underestimation of the aetiologic fraction of asbestos may have been caused by the poor detection of chrysotile. It must also be underlined that differences in sampling, tissue digestion, and methods of microscopy make between laboratory comparison of pulmonary fibre concentration results difficult. ${ }^{8}$

A high prevalence of pleural plaques has been reported in Finland, Bulgaria, and Japan in areas where the bedrock and ground contain anthophyllite. ${ }^{2-41011}$ Endemic plaques have also been reported in populations with environmental exposure to other types of asbestos. ${ }^{1}$ Even a low level of exposure to asbestos seems to be capable of causing an appreciable number of plaques when most of the population has been exposed. The influence of latency is important as most of the exposures in areas of endemic plaques begin in childhood. We found plaques in $58 \%$ of the male urban necropsy cases. Plaques were previously reported in $52 \%$ of the necropsies of Finnish urban dwellers and $32 \%$ of those living in the countryside. ${ }^{4}$ These figures are among the highest that have been reported in random necropsy series. ${ }^{1}$ The results of the present study do not indicate that anthophyllite fibres would be more potent than crocidolite/ amosite fibres to cause plaques. A significant portion of plaques in the Finnish population would still be attributable to anthophyllite, as the number of persons exposed to anthophyllite is higher than the number of those exposed to crocidolite or amosite. ${ }^{12}$ The strong effect of age on the risk estimates of anthophyllite is difficult to explain. It is possible that the pulmonary fibre concentrations may not be equally representative indicators of past cumulative exposure to anthophyllite and crocidolite/amosite fibres, due to possible differences in the pulmonary clearance rates between these fibre types with significantly different average dimensions. Differences in latency may also have confounded the results, as crocidolite was used in Finland mainly in 1955-75 and anthophyllite in 1918-75.9

Pleural plaques have been described among workers exposed not only to asbestos, but also to erionite, attapulgite, wollastonite, and talc. ${ }^{1314}$ We did not find any increased risk of plaques associated with increased pulmonary concentrations of non-asbestos fibres. The other inorgance fibres detected were mainly miscellaneous silicates conforming to the criteria of a fibre; also mullite and rutile were often detected. We do not know whether the concentrations of these fibres represent recent or cumulative old exposures. Due to the small number of samples with an increased concentration of a specific non-asbestos fibre we could not analyse these fibres separately and thus discount the possibility that some of them may cause plaques. The relation between plaques and the non-fibrous inorganic particles was not studied.

Our results support previous findings of an increased risk of plaques among smokers. ${ }^{15-18}$ This finding may, however, have been confounded by different latency times between smokers, ex-smokers, and non-smokers. In a study including adjustment for latency time of asbestos exposure, no risk of plaques was associated with smoking. ${ }^{19}$ In the present material there was no correlation between the pulmonary fibre concentration and smoking. ${ }^{12}$ The risk estimates of smoking were also adjusted for pulmonary asbestos concentration (table 2) suggesting that the possible effect of smoking on plaques is not mediated through an alteration of fibre retention.

As the occurrence of plaques correlates closely with past exposure to asbestos, it is obvious that within a given population, those with plaques should be more exposed on average than those without plaques. This would imply that they are at a higher risk of lung cancer and mesothelioma. The $2 \cdot 5$-fold to 4fold differences in the median of pulmonary fibre concentrations between those with widespread plaques and those without plaques are small compared with the entire spectrum of pulmonary fibre concentrations, ranging from $<0.1$ million $\mathrm{f} / \mathrm{g}$ among unexposed subjects to 100-1000 million $\mathrm{f} / \mathrm{g}$ among heavily exposed patients with asbestosis or mesothelioma. ${ }^{20}$ The epidemiological data on the value of pleural plaques as indicators of cancer risk remain controversial. ${ }^{21-23}$

We thank Ms Tarja Ruotsalainen for her aid in the office routines of the study, and T Kaustia, MA, who did the linguistic revision of the manuscript. This work was supported by the revision of the manuscript. This work was supported by the Finnish Work Environment Fund, the Finnish Found 
1 Järvholm B, Arvidsson H, Bake B, Hillerdal G, Westrin C-G. Pleural plaques-asbestos-ill health. European fournal Respiratory Diseases 1986;68(suppl 145): $1-59$.

2 Kiviluoto R. Pleural calcification as a roentgenologic sign of non-occupational endemic anthophyllite-asbestosis. Acta Radiol 1960;194(suppl): 1-67.

3 Meurman L. Asbestos bodies and pleural plaques in a Finnish series of autopsy cases. Acta Pathologicia et Microbiologica Scandinavica 1966;181(suppl): et 107 .

4 Hillerdal G, Zitting A, van Assenfelt A, Kuusela T. Rarity of mineral fibre pleurisy among persons exposed to Finnish anthophyllite and

5 Central Statistical Office of Finland. Classification of occupations 1987. Handbooks series. Helsinki: Central Statistical Office of Finland, 1987. (In Finnish, English summary.)

6 Tuomi T, Segerberg-Konttinen $M$, Tammilehto $L$ Tossavainen A, Vanhala E. Mineral fiber concentration in lung tissue of mesothelioma patients in Finland. $A m \mathcal{F}$ Ind Med 1989;16:247-54.

7 Mollo F, Andrion A, Pira E, Barocelli MP. Indicators of asbestos exposure in autopsy routine. 2. Pleural plaques and occupation. Med Lav 1983;74:137-42.

8 Davis JMG, Gylseth B, Morgan A. Assessment of mineral fibres from human lung tissue. Thorax 1986;41: mineral

9 Ministry of Labour. Report of the Asbestos Committee. Helsinki: Ministry of Labour, 1989. (Report series of the Governmental Committees No 66). (In Finnish, with English summary).

10 Hiraoka T, Hiro $Y$, Kohyama N, Morinaga $K$. Anthophyllite exposure and endemic plaques in fapan. Proceedings of the 8th International Conference on Occupational diseases, Prague 14:-17.9.1992. Geneva: International Labour Organisation 1993:248-53.

11 Burlikov T, Babadjov L. Ein beitrag zum endemischen auftreten doppelseitiger pleuraverkalkungen. Praxis der
Pneumologie Verreinigt mit der Tuberkulosearzt 1970;24: 433-8.

12 Karjalainen A, Vanhala E, Karhunen P, Lalu K, Penttilä A, Tossavainen A. Asbestos exposure and pulmonary Work Environ Health 1994;20:34-41.

13 International Agency for Research on Cancer. IARC Monographs on the evaluation of the carcinogenic risk of chemicals to humans. Vol 42, Silica and some silicates. Lyon: IARC, 1987:290.

14 Baris YI, Saracci R, Simonato L, Skidmore JW, Artvinli M. Malignant mesothelioma and radiological chest M. Malignant mesothelioma and radiological chest
abnormalities in two villages in central Turkey. Lancet

15 Mcmillan GH, Sheers G, Pethybridge RJ. A radiological follow-up study of the effects of asbestos in dockyard workers in Portsmouth. $\mathcal{f} R$ Nav Med Serv 1978, 64:88-104.

16 Andrion A, Pira E, Mollo F. Pleural plaques at autopsy, smoking habits and asbestos exposure. European fournal of Respiratory Diseases 1984;65:125-30.

17 Weiss W, Levin R, Goodman L. Pleural plaques and cigarette smoking in asbestos workers. F Occup Med 1981;23:427-30.

18 Hillerdal G. Pleural plaques in a health survey material. Frequency, development and exposure to asbestos. Scand $\Im$ Respir Dis 1978;59:257-63.

19 Järvholm B, Sandén $\AA$. Estimating asbestos exposure: a comparison of methods. $₹$ Occup Med 1987;29:361-3.

20 Roggli VL. Human disease consequences of fiber exposures: a review of human lung pathology and fiber burden data. Environ Health Perspect 1990;88: 295-303.

21 Weiss W. Asbestos-related pleural plaques and lung cancer. Chest 1993;103:1854-9.

22 Smith DD. Plaques, cancer, and confusion [editorial] Chest 1994;105:8-9.

23 Nurminen M, Tossavainen A. Pleural plaques and lung cancer: is there an association without asbestosis. Scand $\mathcal{F}$ Work Environ Health 1994;20:62-4.

\section{Destruction of manuscripts}

From 1 July 1985 articles submitted for publication will not be returned. Authors whose papers are rejected will be advised of the decision and the manuscripts will be kept under security for three months to deal with any inquiries and then destroyed. 